\title{
TEORIA, DETERMINAÇÃO, COMPLEXIDADE: DESAFIOS DA REFLEXÃO SOBRE EDUCAÇÃO
}

\author{
THEORY, DETERMINATION, COMPLEXITY: \\ CHALLENGING ISSUES IN THE REFLECTION ON EDUCATION
}

Lílian do Valle 1

Resumo Nas mais diversas modalidades em que se desdobra e em cada região que descortina, ao avançar, o pensamento sobre a educação descobre na existência humana um limite intransponível, o ponto cego de sua atividade. No entanto, ainda assim, a posteridade platônica forneceu alento e atualidade à ilusão da verdade absoluta, e nunca é demais ressaltar o quanto, configurando a organização política moderna, o "mito do especialista no poder" se prolonga nas formas instituídas pelas quais se concebe, se pratica e se pensa a educação. Diante desse quadro por um lado, as respostas já esvaziadas, os velhos conceitos, as lógicas e as teorias explicativas que cedem ante o peso das evidências quotidianas de seu esgotamento; por outro lado, a injunção a desconfiar de todas as respostas, o gozo infantil pela desconstrução - como nos surpreenderia o enorme sucesso que vêm amealhando análises que, sob novas roupagens, oferecem à educação o modelo do mundo natural como parâmetro e instrumental para pensar a "complexidade humana"? Aquilo que, no ser, revela seu caráter magmático ou, como comumente se diz, sua complexidade: como apreendêlo pelo entendimento? O presente texto examina estas questões, propondo como desafio que, para pensar o modo de ser próprio do humano, possamos partir do próprio homem.

Palavras-chave teoria educacional; complexidade; cognitivismo; criação.
Abstract As it develops and expands, in its various modalities and in each new area it opens up, the thought on Education finds in the human existence an insurmountable barrier, the blind spot in its activity. Nevertheless, Plato's succeeding generations have given a new breath of life to the illusion of absolute truth and even updated it. Therefore, it is never enough to emphasize how much 'the myth of the specialist in power' that gives shape to modern political organization, also extends to the institutionalized ways in which we conceive and practice education or even think about it. In this scenario - on the one hand, the already emptied answers, the old concepts, the logic and the explicative theories that fall under the weight of the everyday evidences of their exhaustion; on the other, the demand to mistrust all answers and the childish pleasure in deconstructing - how could we be surprised by the huge success being obtained by analyses that - under new clothing - offer to education the model of the natural world as a parameter and as a tool to help its understanding of the "human complexity"? How can we apprehend through our understanding something that, in its being, reveals its igneous character or, as it is usually said, its complexity? The present text looks at these issues and proposes, as a sort of challenge, that, in order to reflect upon the way of being that is peculiar to human beings, we should start with the human being him/herself. Key words educational theory; complexity; cognition; creation. 
Se me for permitido dizer algo que, a meu ver, não é apenas um gracejo, eu diria que chegou a hora, talvez, de inverter o procedimento tradicional. Em vez de tentar descobrir em que medida é possível explicar o que sucede ao homem por meio da física e da biologia e, por exemplo, prosseguir supondo que uma idéia, um mito, um sonho não são mais do que resultados epifenomenais de um certo estado do sistema nervoso que seria, por sua vez, redutível a, digamos, um certo arranjo de elétrons, poderíamos talvez tentar, com finalidades heurísticas, inverter o procedimento. Todos se recordam que, quase sempre, os filósofos começam dizendo: “Quero saber o que é o Ser, o que é a realidade. Ora, eis aqui uma mesa; o que é que essa mesa me exibe como traços característicos de um ser real?" Jamais qualquer filósofo começou dizendo: “Quero saber o que é o Ser, o que é a realidade. Ora, eis aqui minha lembrança de meu sonho da noite passada; o que é que ela me exibe como traços característicos de um ser real?"' (Castoriadis, 1987, p. 227).

Nas mais diversas modalidades em que se desdobra e em cada região que descortina, ao avançar, o pensamento sobre a educação descobre na existência humana um limite intransponível, o ponto cego de sua atividade. Oferecida como epígrafe para um texto que pretende pensar alguns dos impasses que se apresentam à reflexão sobre a educação, é bem possível que, à primeira vista, a afirmação de Castoriadis, na longa citação à qual me permiti, pareça uma solução de facilidade, que muitos estariam prontos a receber sem maiores reservas: e, de fato, quantos problemas estariam superados se pudéssemos, simplesmente, começar por nosso "sonho da noite passada" - por nossa mais pura subjetividade - oferecendo-a como parâmetro e como modelo para a reflexão sobre a realidade? Alguns, entretanto, insistiriam em afirmar a necessidade de se buscar, no enfrentamento com o real, o rigor e a objetividade compatíveis com o conhecimento científico.

Assim, a supor que estivéssemos no caminho certo, a citação nos deveria reconduzir a um antiqüíssimo e muito vasto dilema entre subjetividade e objetividade - que, pelo menos desde Heráclito, acompanha a história do conhecimento humano. Tomando-se a questão desse ponto de vista, assim deveríamos formular o problema da validade, ou das condições de validade do conhecimento humano - que, sob as mais diferentes encarnações, jamais deixou de estar presente na história do pensamento.

O exame do caso mais específico da educação talvez nos demonstre, entretanto, o proveito de não reduzir as possibilidades de uma discussão antes mesmo que ela se estabeleça. É bem verdade que, também na área educacional, esse debate até hoje faz-se presente, traduzindo, por vezes, duas posições extremas, mas nem por isso menos recorrentes. A primeira disposta a enfatizar a experiência - que sempre é local, acidental, singular, particular e, até certo ponto, incomunicável — como esteio e como limite para o saber; 
a segunda, a insistir sobre a universalidade, sobre a essencialidade, sobre a comunicação e sobre a prova como garantias para o conhecimento válido.

Situar todo o problema sob essas bases significaria, entretanto, ocultar - como até certo ponto vem-se fazendo correntemente - uma questão que permanece essencial e que se refere à decisão de tratar a educação, primordialmente e acima de qualquer outra coisa, como um "saber". Muito embora sejam poucos o que ainda hoje ousariam afirmar que a atividade educativa é uma mera aplicação das regras, procedimentos e técnicas que se podem deduzir de um conhecimento anterior e prévio, uma extraordinária coincidência de pontos de vista e de interesses têm convergido para a sobrevalorização da dimensão cognitiva - da qual a redução de todas as atividades humanas à "construção de saber" é apenas uma face.

Se tal tendência pode, de fato, ser afirmada, ela talvez ajude, paradoxalmente, a explicar porque tantos, hoje em dia, reagindo aos limites que a realidade humana impõe aos esforços elucidativos daquele que a interroga, parecem dispostos a renunciar ao que a educação e o pensamento sobre a educação necessariamente implicam: a possibilidade de elucidação, de coerência, de construção de sentidos que, mais do que singulares e próprios, possam ser oferecidos a outrem, possam ser dados como base para a construção de um entendimento que vá além de minha experiência idiossincrásica, de meu universo particular de sentido.

O grande precursor da hierarquização que estabelece a primazia do conhecimento sobre todas as demais atividades humanas é, sem dúvida, Platão. Não é preciso muito para perceber que a valorização do conhecimento teórico em detrimento do conhecimento prático está na base da desqualificação a que Platão pretende submeter publicamente tanto a política democrática, quanto a educação que lhe corresponde, promovida pelos sofistas. Indo mais além, observa-se que essa valorização está assentada, ela própria, sobre a idéia de que não somente é possível um saber certo e infalível sobre a educação (e sobre a política), mas que esse saber é o único que deve guiar sua realização.

Assim, em oposição à prática dos sofistas — que era indissociável dos debates públicos a que era submetida no regime democrático, mas incapaz de fornecer a definição prévia e acabada que Sócrates, nos diálogos, exigia - Platão afirma a necessidade de uma investigação meticulosa e previamente determinada acerca das finalidades como condição e critério de validade para qualquer educação.

Essa concepção segundo a qual a atividade educativa deve ser regida por um conhecimento anterior e externo a ela vai, até certo ponto, ser abalada pela crítica moderna, que descobre, juntamente com a afirmação da liberdade humana e pela primeira vez desde o declínio da primeira sofística, o caráter paradoxal da educação: não seria contraditório educar para a au- 
tonomia? Ainda que afirmando todo o contrário, Kant, como é sabido, vai insistir sobre o caráter prático da chamada "pedagogia".

E muitos foram os que creditaram à herança moderna a vitória sobre o modelo metafísico que, até seu apogeu, no século XVII, dominou a educação, encarregando-se de provê-la de definições teóricas prévias e acabadas sobre sua natureza e seus fins:

“(...) o declínio do modelo metafísico da pedagogia (...) tinha começado entre os séculos XVII e XVIII, com Locke, aumentando depois com Rousseau e Kant, com o romantismo e o positivismo, para expandir-se em nosso século, onde permaneceu como apanágio de posições que não eram de vanguarda, embora combativas e religiosas (como o idealismo, como muito pensamento católico, neo-escolástico ou espiritualístico). A centralidade da especulação filosófica como guia da pedagogia foi substituída no pensamento contemporâneo pela centralidade da ciência, e de uma ciência autônoma, cada vez mais autônoma em relação à filosofia" (Cambi, 1999, p. 402).

No entanto, não é difícil perceber que a confiança ilimitada nessa "ciência autônoma" acompanhou a reconstituição, se tanto se pode dizer, do ideal de um saber todo-poderoso, incidindo sobre a área educacional sob a forma de um ímpeto tecnicista e planificador que, de novo, a reduziu a terreno de mera aplicação de teorias.

Muito já se comentou sobre essa posteridade platônica, que forneceu alento e atualidade à ilusão da verdade absoluta - feita agora ciência, saber inquestionável — de modo que não será preciso sublinhar ainda que o controle que pretendeu exercer sobre a realidade não se limitou à dimensão teórica, mas erigiu-se como poder sobre as coisas e sobre os homens. Mas nunca é demais ressaltar o quanto, configurando a organização política moderna, o "mito do especialista no poder"2 se prolonga nas formas instituídas pelas quais se concebe, se pratica e se pensa a educação.

\section{Teoria e interrogação sobre o homem}

Em sua versão mais contemporânea, a exigência de estabelecimento de um discurso especializado mergulhou a teoria educacional na busca das expressões mais propícias à aquisição de um vocabulário técnico, de conceitos, de grades analíticas, de correntes de pensamento. Resulta daí uma verdadeira revolução do campo educacional, que passa a buscar apropriar-se de teorias oriundas das mais diversas áreas do conhecimento.

Nem sempre, infelizmente, essa abertura se fez acompanhar de um cuidado redobrado de investigação dos pressupostos e axiomas que, juntamen- 
te com o instrumental conceitual e analítico, se estava insidiosamente impondo à reflexão educacional. Atividade abstrata de especialistas, essa reflexão chega aos não-iniciados - àqueles que praticam cotidianamente a educação - sob a forma de leitmotiven, traduzida em grandes teses intelectuais e em modismos que, ao invés de favorecer, muitas vezes obstruem a reflexão autônoma.

Pois há muito a área da educação já não investe nas interrogações sobre o homem com quem trata e que é o centro de sua atividade, o que tem reflexos bastante claros sobre as formas correntes de se considerar o professor, o currículo, a história, as leis e seu caráter instituinte, as teorias e métodos educativos e, é claro, o aluno. Isso se deve, em grande parte, ao fato de que todas essas questões parecem já ter sido satisfatoriamente resolvidas pelas teorias científicas a que os especialistas fazem recurso; e de que os educadores, quanto a eles, simplesmente não acreditam ser sua tarefa colocar em questão esses fundamentos sobre os quais assentam-se sua formação e as "teorias" que lhes são regularmente servidas.

Mas é preciso considerar, ainda, o peso das resistências que, no próprio âmbito da teoria, se opõem à reflexão sobre o humano e que, derivadas dos excessos da crítica à metafísica, elaboram-se como uma espécie de interdito lançado sobre a questão: quem é (não o Homem genérico, mas, a cada vez) esse homem que a mim se apresenta, e o que ele mantém em comum com os outros homens? Decerto, sob pretexto de enfrentar o problema humano, a tradição filosófica estabeleceu os dogmas e forneceu justificação para a dominação social.

Nesse sentido, uma das mais fortes contribuições do século XX talvez seja seu trabalho de crítica a essa tradição, cujos limites, cujos compromissos e cujas perversões alguns autores souberam tão bem denunciar, ao mesmo tempo em que afirmavam a abrangência e formidável complexidade dessa simples indagação. No entanto, em que a convicção de que não há, nem pode haver, uma resposta acabada, deveria implicar no afastamento de qualquer indagação acerca do homem?

Ao menos no campo da teoria educacional, o vazio que se sucedeu à crítica filosófica da metafísica moderna teve como implicação uma profusão de textos que reiteram incessantemente seus principais argumentos, relativos à recusa do dogmatismo ontológico e dos "discursos prescritivos". A esses vêm somar-se toda uma série de contribuições pedagógicas inovadoras, que recebem por parte das autoridades educacionais e dos professores uma acolhida de dimensões somente comparáveis à urgência dos desafios que pesam sobre a educação.

De forma geral, essas propostas descrevem uma situação de crise, elegendo uma habilidade ou um atributo que, em seu entender, foi ou tem sido negligenciada na educação do aluno ou do professor: falta-lhes a reflexão, ou 
a abertura à diferença, ou a sensibilidade ética, a atenção ao caráter transversal, transdisciplinar e prático do saber... Porém, na ausência de qualquer discussão propriamente ontológica - da interrogação explícita sobre o ente do professor e do aluno, permanecem inalteradas as bases antropológicas sobre as quais se instituiu a educação na modernidade. Isso tem como efeito prático o fortalecimento de antigos esquemas antropológicos e imagens mentais que, provenientes da tradição filosófica rejeitada, não deixam de ser alimentados pelo cientismo de que os estudos educacionais ainda padecem.

Em outras palavras, se o sujeito pós-moderno se dissolve no perpétuo conflito entre a glossolalia das abstrações e a mudez da realidade empírica, o sujeito moderno, quanto a ele, porta-se bastante bem, e talvez uma das evidências mais flagrantes de sua permanência é a hiper-valorização da dimensão cognitiva, que pode ser reconhecida nas teorias e discursos sobre a educação.

Desse privilégio decorre o abandono de qualquer preocupação com a ordem das sensações (a menos que seja para assentá-las como base para o desenvolvimento das funções cognitivas); decorre também a exterioridade com que até hoje se trata do problema da consciência e do pensamento (dados como realidades evidentes); a recusa quase sintomática de apropriação das contribuições mais correntes da psicanálise; a superficialidade de sua reflexão sobre a ética; suas dificuldades em enfrentar os problemas que a noção de natureza ainda introduz, sobretudo quando se trata de pensar a igualdade e a alteridade do ponto de vista da prática educativa.

O presente artigo não pretende, é óbvio, fornecer essas "novas bases antropológicas" para o discurso educacional ou, ainda, fornecer explicações que permitam desvendar de uma vez por todas o enigma humano de que trata a educação. Longe de lá, em vista do grande panorama aberto pela questão antropológica e do interesse apenas relativo que vem despertando na reflexão educacional, o primeiro passo parece ser voltar a esse sujeito moderno, supostamente ultrapassado, mas que suspeitamos estar ainda fortemente presente entre nós.

Nascido na confluência de uma soma admirável de perspectivas filosóficas as mais distintas e mais ou menos influentes na área da educação, esse sujeito certamente não é uma criação da filosofia, mas emerge como um dos primeiros produtos da forte confluência de interesses e disposições que levaram, na modernidade, à redescoberta da razão humana. O traço mais marcante desse sujeito - pelo qual se deu predominantemente a conhecer, na educação, e pelo qual ainda o reconhecemos na atualidade, é a cognição. Como dissemos, sobretudo no que se refere à área educacional, esse atributo adquire tal vigor e centralidade, nos discursos, práticas e procedimentos pedagógicos, que passa a monopolizar o sentido da educação, redefinindo inteiramente a concepção de aluno e de professor. 
Se houvesse que se retraçar brevemente a história da emergência desse que passa a ser, centralmente, $o$ sujeito da educação, seria preciso dizer que as condições de seu nascimento foram prenunciadas quando, sob a tríplice influência da tradição cristã - que se exerceu pela releitura sistemática e "autorizada" do pensamento clássico, pelo monopólio quase absoluto da autoridade intelectual e pela ampla atuação educativa - consolidou-se uma apropriação muito específica da herança da Antigüidade, que pôs em relevo a marca metafísica, em detrimento da experiência de interrogação democrática que também a caracterizava; que introduziu uma ruptura radical entre dimensões que o pensamento grego se limitara a hierarquizar (corpo e alma, sensação e razão, ética e sentimento); e que, negando a essa herança seu enraizamento político, estabeleceu de maneira definitiva o conflito entre as dimensões privada e pública da existência humana.

Mas é hoje quase uma tautologia afirmar que o sujeito moderno começa a ser engendrado sob a influência do Iluminismo e sua crítica radical aos dogmas e preconceitos instituídos sob forma de uma tradição que, como os homens das Luzes não deixaram de observar, não hesitava em se comunicar através dos sentimentos, buscando tocar os corações e as almas.

A educação moderna descobriu, assim, sua vocação de só falar à razão, que cabia, agora, instruir. Não foram suficientes os protestos de Rousseau: sob a égide de um projeto de racionalização que Descartes já proclamara, e que o liberalismo investirá como sua própria essência, subordinam-se todas as dimensões humanas àquela que mais parece corresponder ao seu ideal de controle. Modulado pela aspiração ao domínio ilimitado que as perspectivas de desenvolvimento da ciência e da técnica propiciavam, o conhecimento ganha uma nova acepção e se transforma em ideal humano, virtude social e princípio de identidade.

A rigor, as bases do programa se encontravam consignadas em Descartes: é preciso desencantar o mundo para melhor dominá-lo. Para isso, o homem tem à sua disposição a arma do entendimento puro: “(...) concebemos os corpos pela faculdade de entender o que está em nós, e não pela imaginação ou pelos sentidos; não os conhecemos pelo fato de vê-los, ou tocá-los, mas somente porque os concebemos pelo pensamento" (Descartes, s/d, p. 324). O entendimento exige, assim, o controle não só dos sentimentos, mas das sensações que ordinariamente experimentamos. O conhecimento desdobra o sujeito em um observador exterior e neutro, porque enfim capaz de dominar-se.

Esse desdobramento do sujeito toma corpo em Locke - que, para E. Balibar, deve ser dado, e não Descartes, como o grande protagonista da invenção da consciência (Balibar, 1998). O sujeito dessa reflexão, desse exame de sua própria atividade mental, é um "outro" tornado, por assim dizer, diferente de si: e não importa que mais tarde ele seja dado, por Kant, como pu- 
ro paralogismo: ele inaugura essa condição desencarnada e artificial da razão moderna. Pois, partindo tão somente das sensações simples e da consciência de si, o homem lockiano tem diante de si um longo caminho, de disciplina e método, de controle de sua própria natureza, até chegar ao conhecimento racional:

“O sujeito do desengajamento e do domínio da razão tornou-se para nós uma figura familiar da modernidade. Poder-se-ia quase dizer que ele se tornou uma das maneiras de nos interpretarmos a nós mesmos, da qual temos dificuldade em nos desfazermos... esse sujeito atinge seu pleno desenvolvimento (...) em Locke e nos pensadores das Luzes que ele influenciou (...). A característica desse sujeito é de atingir o domínio pelo desengajamento" (Taylor, 1998, p. 212).

O domínio, que é antes de tudo domínio de si, traduz-se em racionalidade: e, esta, em capacidade de aquisição do saber. Tal como em Locke, em Kant a razão nada tem de imediatamente natural. Ainda que se constituindo em atributo universal, isso é, naquilo que os homens têm em comum, a razão autônoma é uma vitória sobre a animalidade: por isso, é somente através da cultura - e propriamente através da educação, pela qual “o homem será 'disciplinado' (domado), 'cultivado' (instruído), 'civilizado' (prudente) e 'moralizado' (apto a escolher bons fins, isso é, fins universalizáveis)” (Cassin, 1999, p. 115) - que a razão se descortinará.

Porém, afirma Castoriadis, o ego transcendental kantiano “(...) estabelece uma clivagem abissal entre sujeito transcendental e sujeito psicológico":

“Aquele é suposto (postulado) funcionar sob o único requisito da produção de julgamentos a priori; este está submetido às leis da psicologia empírica, emitindo, portanto, julgamentos, não motivados, mas determinados (no sentido das ciências da natureza) por causas psíquicas. (...) No campo do conhecimento, em todo caso, essa alma empírica não poderia ser senão fonte de perturbações e erros, quando, por exemplo, a 'imaginação empírica' ou, pior ainda, as paixões, interferem (mas pergunta-se como) no funcionamento da consciência transcendental" (Castoriadis, 2000, p.138).

Estabelecido pelo domínio sobre as disposições naturais, sobre sentidos, sobre a psicologia e as paixões - em suma, sobre sua condição empírica , o sujeito cognoscente adquire, por força do culto à racionalidade, a dignidade de conceito abstrato e de modelo antropológico. Mas este modelo não é obra solitária de filósofos: ele é produto de um mundo que não somente se quer desencantado, mas inteiramente voltado para o progresso material, em nome do qual os indivíduos são chamados a abdicar da vida pública — da "liberdade dos antigos". 
H. Arendt analisou as conseqüências do desaparecimento, no mundo moderno, das esferas privada e pública, anteriormente constitutivas da existência humana: o estabelecimento, por um lado, de uma "privaticidade" esvaziada e muda e, por outro, de uma prática social que, não mais permitindo a experiência política da pluralidade e da singularização, se reduz a comportamento estereotipado (Arendt, 1987, p. 48), a uma conduta uniforme e plenamente racionalizável:

“A uniformidade estatística não é de modo algum um ideal científico inócuo, e sim o ideal político, já agora não mais secreto, de uma sociedade que, inteiramente submersa na rotina do cotidiano, aceita pacificamente a concepção científica inerente à sua própria existência" (Arendt, 1987, p. 53).

Segundo a arguta observação de H. Arendt, a consolidação dos Estados como instâncias especializadas de realização de uma tarefa de cunho estritamente "administrativo" só pôde ser plenamente efetivada em sociedades onde o que une os homens já não é mais a atividade política - pela qual, construindo uma esfera comum de existência, constroem-se também como seres públicos - mas antes a coincidência de interesses estritamente relativos à esfera das atividades de sobrevivência material, implicada pela generalização do modelo familiar, econômico de vida.

Nessa perspectiva, caberia ainda associar a construção desse sujeito moderno que vimos questionando à emergência do ideal "político" de uniformização das condutas, prontamente retraduzido em termos educacionais na tarefa de modelagem das subjetividades modernas que coube, desde os primeiros tempos, a essa outra criação da modernidade: a Escola Pública.

Pode-se, assim, estabelecer uma relação nada casual entre, por um lado, as exigências de construção das sociedades modernas, que levam à criação da Escola e a sua adoção como modelo universal da prática de educação pública e, por outro, a sistemática racionalização dos sujeitos da ação escolar, aos poucos inteiramente reduzidos a sua dimensão cognitiva. Em primeiro lugar, essa relação pode ser justificada pelo fato de que, chamada a monopolizar o grosso das iniciativas educacionais modernas, a Escola Pública é uma das primeiras manifestações da modernidade que vimos descrevendo, fazendo-se, pois, legitimamente tributária das expectativas, dos projetos, dos mitos e das obsessões que passam a marcar o período.

Porém, é preciso convir que, ademais, na medida em que realiza a conversão da complexa tarefa de formação humana à sua expressão objetiva e racionalizável, propondo os termos a partir dos quais os objetivos da educação finalmente podem ser, como se diria mais tarde, operacionalizáveis, a redução cognitivista se torna a verdadeira conditio per quam da Escola Pública moderna. Ela é, assim, instrumento essencial para a legitimação da ativida- 
de dos especialistas que, por meio da administração racional, tanto quanto da teorização da educação, pretendem legislar (de cima e de fora) sobre a prática escolar, convertendo-a, e aos tipos antropológicos a ela associados, em objetos amplamente determináveis e determinados pelas disposições normativas.

A perspectiva histórica talvez ajude a compreender o renitente apego que a teoria pedagógica e o discurso oficial sobre a Educação até hoje demonstram pela redução cognitivista e seus instrumentos de predileção:

- os documentos legais, de caráter técnico-normativo e eternamente condenados pela contradição entre as ilusões que entretêm quanto a seu poder instituinte e as evidências de sua ineficácia, a desdobrar seus neologismos eruditos em uma profusão infindável de explicitações, comentários, estudos, manuais de aplicação;

- a transposição curricular universal, pela qual a formação ética, a construção das subjetividades, o treinamento das habilidades de socialização, a aquisição de sensibilidades, afetos e gostos específicos se fazem objetos de uma abstração destinada, inicialmente, a instruir o professor e, em seguida, à aplicação prática;

- as grades avaliativas, estatísticas e testes objetivos que, alternando-se à "subjetividade" dos conceitos e categorias teóricos, procedem ao ordenamento de toda atividade escolar segundo o único princípio da instrução: somente ela, se faz, por esses meios, verificável.

Porém, o recrudescimento atual do cognitivismo - que corresponde ao “desinvestimento" do caráter político da educação pública, à renovação do mito do especialista, ao esvaziamento dos espaços de construção coletiva e, mesmo, à valorização da iniciativa privada como alternativa para a responsabilidade pública pela educação — não pode ser dado como mera fatalidade, que apenas prolonga as características desde sempre identificáveis no modelo original da educação escolar.

O cognitivismo é ainda hoje uma construção social. No entanto, diferentemente do passado, essa construção não mais se apóia em uma árdua e consistente elaboração antropológica, mas, paradoxalmente, em sua ausência. A superficialidade das concepções de homem, de aluno e de professor que presidem numerosos discursos educacionais acompanha o empobrecimento da vida social e a "escalada da insignificância" em que mergulhou a reflexão em nossas sociedades. Na educação, mas não só aí, ela contribui para manter vivo o mito da atuação especializada do legislador, do administrador e do teórico, em substituição às incertezas da construção política, da deliberação coletiva, da iniciativa autônoma, empírica e singular. 


\section{A descoberta da complexidade}

Ao oferecer respostas acabadas e cada vez mais redutoras para as questões com que tratavam, sem dúvida as teorias modernas contribuíram para o esvaziamento das enormes questões com que cada um de nós se defronta, na reflexão e na prática educacional. Nesse sentido, a reação pós-moderna tem o mérito de reintroduzir questionamentos essenciais e, através dele, a própria vocação crítica do pensamento.

No entanto, recusar as grandes sínteses e formulações, que seccionam a especificidade humana para em seguida dissolvê-la na incorporeidade de uma universalidade inexistente, não implica necessariamente a denegação da interrogação, antes pelo contrário. Entre a aspiração ao controle absoluto - de que a ênfase na determinidade, por parte do pensamento moderno, é apenas um dos sintomas - e a abdicação radical de qualquer tentativa de construção comum, tanto no âmbito do entendimento, quanto no âmbito da ação, tal como pode ser vislumbrada em muitos discursos atuais, há uma enorme distância, continuamente verificada por aqueles que não desistiram de se comprometer com os desafios da educação.

Diante desse quadro - por um lado, as respostas já esvaziadas, os velhos conceitos, as lógicas e as teorias explicativas que cedem ante o peso das evidências quotidianas de seu esgotamento; por outro lado, a injunção a desconfiar de todas as respostas, o gozo infantil pela desconstrução - como nos surpreenderia o enorme sucesso que vêm amealhando análises que, sob novas roupagens, oferecem à educação o modelo do mundo natural como parâmetro e instrumental para pensar o humano?

A apropriação indiscriminada de metáforas, conceitos e categorias provenientes das ciências naturais ou físicas - da teoria dos conjuntos, das teorias do caos, dos fractais, das análises topológicas etc. — revelam, para além da saudável descoberta da complexidade humana e social, não só nossa demissão frente à angústia da interrogação, mas nosso esquecimento das lições de nossa própria história. Eis como a constatação da provisoriedade e da incompletude do conhecimento instituído tem servido de argumento para a relativização das exigências e peculiaridades da reflexão sobre o homem.

No entanto, o fato de que o humano é complexo e enigmático deveria, antes, nos conduzir a redobrar a vigilância em face dos métodos, dos procedimentos, dos critérios que utilizamos para organizar o que, no humano, é organizável, para formalizar, sob a forma de teoria, o que, no humano, é passível de formalização teórica.

Entendida como condição dos entes naturais, a complexidade coloca em evidência os limites de uma lógica que, amplamente presente nas mais diversas formas de organização a que submetemos a realidade, teve seus pressupostos lógico-ontológicos consignados por Aristóteles: os princípios da 
identidade, da não-contradição, do terceiro excluído; da equivalência entre propriedade e classe (possibilidade de operação classificatória); das relações de equivalência, de ordenação; da determinidade (Castoriadis, 1987, p. 398). Com base nessa lógica, que Castoriadis denominou "conjuntista-identitária", e que tem na teoria dos conjuntos sua versão matemática, trabalha não só a ciência, mas cada um de nós, em nossas mais simples operações quotidianas - mas também, até certo ponto, em nossos sonhos, na literatura, na simbolização, no mito. De outro modo, como poderíamos sequer falar dessas experiências e de seus produtos?

Assim, se é verdade que os operadores em que a "lógica tradicional" se apóia não são suficientes para pensar todos os aspectos da realidade natural, também é certo que eles, longe de poderem ser ultrapassados, têm uma inegável efetividade no domínio da existência, correspondendo a, pelo menos, uma dimensão do ser:

“(...) a lógica conjuntista-identitária repete, prolonga, elabora... uma parte essencial da lógica do vivente. Sem dúvida, em uma imensa parte de suas operações (...) o vivente opera por meio de classes, propriedades e relações" (Castoriadis, 1987, p. 415).

Face à complexidade e contra a lógica conjuntista-identitária (em sua forma matemática ou, por exemplo, em suas formulações topológicas) deve-se afirmar que "o que existe não é conjunto nem sistema de conjuntos" (ibid., p. 116), nunca é plenamente determinado, ou exaustivamente determinável; tampouco o que existe é puro caos, mas comporta uma dimensão conjuntista-identitária "ubiquamente densa" (ibid.). À capacidade humana de atribuir sentido às coisas e de constituir seu mundo como sentido - e não como puro caos - corresponde esse "estrato" da realidade que se presta à organização conjuntista-identitária e isso vale para uma ampla dimensão da existência dos homens e das sociedades.

Para os interesses da presente reflexão, duas questões se colocam: a primeira, que havíamos abordado logo de início, refere-se a saber até que ponto a realidade de fato comporta essa organização conjuntista-identitária, não sendo nós que a impomos. Ora, dizer, como o faz Castoriadis, que “(...) para o observador, a questão de saber, num sentido último, o que provém de si mesmo e o que provém do observado é indecidível (...)" não é o mesmo que afirmar que tudo é subjetividade, que vivemos mergulhados na impossibilidade de não só romper com os sentidos que nossa subjetividade nos apresenta (que são nossos, mas desde quando e a partir do que?), mas igualmente de compartilhar de sentidos que nos são apresentados.

Se não somos forçados a proclamar que todos os saberes (não importa quais e em vista do que) se equivalem - e, portanto, a anunciar a futilidade 
de nossas reflexões e do próprio desafio da educação - é porque podemos, mediante um esforço deliberado e coletivamente aceito, submeter o que para nós se constitui em sentido ao exame de suas condições e limites de validade. A "superação da lógica tradicional" não é, pois, recusa das exigências que o pensamento se dá a si próprio na intenção de ir mais longe: é o caminho árduo que é preciso empreender para não escravizá-lo aos sentidos mais imediatos, mais redutores e mistificados que a realidade pode ter para nós.

Por isso, a segunda questão, muitíssimo mais vasta e relevante, se volta para o que, na realidade, não se deixa apreender pelos esquemas de determinidade, pela lógica conjuntista-identitária, mas se constitui no que Castoriadis denominava a dimensão poética, imaginária do ser. Aquilo que, no ser, revela seu caráter magmático ou, como comumente se diz, sua complexidade: como apreendê-lo pelo entendimento? Pois, no caso do humano, seria insuficiente e, mesmo, ingênuo responder que tudo se resumiria à tentativa de "reproduzir" os graus de incerteza e de indeterminação da realidade.

É essa a grande diferença, a diferença fundamental, que a interrogação sobre o homem introduz: na dinâmica do conhecimento exato, o que escapa à determinação revela os limites intransponíveis do entendimento. No entanto, na dinâmica que a existência humana deixa perceber, o que escapa à determinação aponta para as possibilidades inesgotáveis de criação, individual e coletiva:

“A não determinação do que existe não é simples 'indeterminação' no sentido privativo e, em última análise, trivial. Ela é criação, a saber, emergência de determinações diferentes, de novas leis e de novos domínios que se submetem a elas. A 'indeterminação' (na medida em que ela não é entendida apenas um 'estado de nossa ignorância', ou uma condição 'estatística') tem esse sentido preciso: nenhum estado do ser pode ser tal que venha a tornar impossível a emergência de determinações diferentes das que já existem" (Castoriadis, 1987, p. 417).

Eis, pois, com o que me deparo, quando penso em "minhas lembranças de meu sonho de ontem à noite": para além da lógica conjuntista-identitária que ali não deixa de estar presente (eu tenho medo e corro; a chuva me molha; alguma coisa cai e se quebra), há um enorme fluxo de sentidos que escapam não só às minhas lembranças, mas, em minhas lembranças, a todas as fórmulas que conheço para pensá-las e reproduzi-las. Paradigma radical da criação, em meu sonho eu sou, estranhamente, eu e o oposto de mim; há, no modo de ser de nosso sonho, como assinala Castoriadis (1987:50) uma subdeterminação e uma sobredeterminação dos significantes, paralela a uma subsimbolização e a uma sobresimbolização das significações etc.

Nada que, nem de longe, faça pensar no conjunto cantoriano, com seus elementos claros e discerníveis, de atributos definíveis e mantendo relações 
definíveis, ainda que múltiplas e em múltiplas direções, com outros elementos, subconjuntos e conjuntos. O que se passa então - como a psicanálise, que também começou pelo sonho, pôde verificar - permite entender que, no que se refere à existência humana, não há "ciência" que permita explicar ou formalizar essa criação ininterrupta de sentidos, não há saber capaz de me revelar inteiramente o que se passa em meu próprio sonho. E, se esse sonho não é inteiramente determinado por alguma força oculta exterior a mim, devo entender que essa criação é minha imaginação radical.

O sonho, portanto, como fluxo significativo, ininterrupto e inexaurível, que me revela algo sobre a criação de um mundo próprio pelo vivente. Avancemos, então, mais um passo: seja meu sonho paradigma para pensar a existência e a especificidade humana - para a qual, diferentemente dos animais e das coisas, a autonomia não é fechamento em um sentido originário (psíquico ou sócio-histórico) mas, muito pelo contrário, a própria possibilidade de questionamento desses sentidos instituídos e de instituição de novos sentidos. Seja meu sonho o paradigma para pensar a existência de entes o homem, a sociedade - para os quais a indeterminação não é o caos, mas a possibilidade de criação de novas determinações.

Seja meu sonho de ontem à noite desafio para pensar o modo de ser próprio desse ser que, rompendo com o círculo de fechamento que caracteriza a subordinação dos viventes às leis mudas de sua existência, inventa como sentido para si o questionamento, a deliberação e o projeto de autonomia humana - individual e coletiva. Seja a lembrança de meu sonho de ontem a noite uma injunção para que possamos, enfim, estabelecer o humano como paradigma para a existência humana.

\section{Pensar a existência humana}

O homem não é uma máquina calculante, ele é sentido encarnado, fluxo ininterrupto de criação e possibilidade de criação deliberada, de autonomia. No domínio educacional, apesar dos excessos a que foi submetida pelos usos que recebeu, a crítica à ideologia dos especialistas realizada a partir da década de 1970 teve o grande mérito de denunciar a redução da dimensão política à técnica. Muito longe de esgotadas, ou ultrapassadas, as questões que então se levantaram parecem, retrospectivamente, ter sido simplesmente abandonadas tal o sucesso que novas formas de tecnicismo e de pragmatismo sutil ou rudimentar amealham atualmente entre nós.

Soaria muito óbvia a afirmação de que não se está pregando a dependência da reflexão educacional ao puro senso comum? E de que a crítica ao mito do especialista não só não conduz forçosamente à noção de que tudo é saber e de que todas as formas de "saber" educacional se equivalem, como 
busca questioná-la? Todo cuidado é pouco para, ainda aqui, evitar o falso dilema entre o ideal da determinação absoluta e a total indeterminação que, nesse caso, tomaria a forma pouco criativa de um impasse entre, por um lado, a aceitação de que o sentido da educação possa ser exaustivamente ou mesmo predominantemente fornecido pelo conhecimento teórico e, por outro, a recusa da validade e relevância de um conhecimento especializado e rigoroso sobre a educação.

É possível que uma parte do problema esteja em discernir o que haveria na educação que, concernindo ao homem e à sua existência, estaria inteiramente determinado, podendo ser, portanto, objeto de um saber exato e rigoroso; e o que, não estando inteiramente determinado, dependeria ainda da deliberação (da criação humana), não se fazendo apenas objeto de saber, mas, sobretudo, de instituição ${ }^{3}$.

Essa reflexão provavelmente nos conduziria a perceber que, na criação dos sentidos da educação, o conhecimento rigoroso daquilo que está inteiramente determinado no homem - relativo às características biológicas e físicas de sua existência - tem uma importância bastante reduzida. E também que o discernimento do que, sendo criação humana, social-histórica, se apresenta como inteiramente determinado - isso é, que o desvelamento do caráter instituído de certas significações, que se dão por determinações absolutas e intransponíveis, é um dos grandes trabalhos a serem continuamente retomados pela reflexão educacional.

Aparece como corolário que as decisões de sentido, que a atividade pública - de criação dos sentidos da educação deve ser, ela própria, objeto de um conhecimento: mas que características dever-se-ia atribuir a esse conhecimento? Dizíamos que pretender estabelecer uma "ciência da criação de sentidos" é uma aberração: no entanto, é bem disso que se trata, a cada vez que se reduz o conhecimento sobre educação a um saber exato. Porém, e inversamente: abdicar da tarefa de reflexão e crítica sobre o modo como, em nossa sociedade, a educação é prática e teoricamente instituída, abdicar dos instrumentos que podem tornar essa reflexão mais aguçada, mais profunda, mais pública é obrar em favor da alienação.

Porque a complexidade, no ser humano, não encontra paralelo, nem nos astros, nem nas moléculas. O pensamento sobre a educação é fugidio, incompleto, fragmentário, insuficiente; ele avança criando suas próprias condições de validade, e não fugindo dessa discussão - que Castoriadis abordou, ao dizer que a deliberação democrática é aquela que está submetida ao lógon didonai: à exigência dar conta e prestar contas.

Assim, na medida em que se busca discernir o que, na educação, refere-se a uma deliberação humana - e, portanto, o que é objeto de prática política, e não de reflexão teórica — redescobre-se o sentido que a educação só pode adquirir na democracia: não um campo de aplicação de um co- 
nhecimento exaustivamente formalizável, exato - que, como tal, deve ser inteiramente deixado a cargo dos especialistas - mas como atividade instituinte de sentidos que estão longe de serem apenas teóricos ou técnicos. Sentidos que concernem à autocriação permanente dos sujeitos que somos, professores e alunos.

Ocorre que, atividade eminentemente pública, a prática educativa que institui ou encarna os sentidos da educação deve ser submetida a um questionamento radical: há condições, a serem examinadas, para que esses sentidos sejam ou possam ser tornados públicos. O modelo, aqui, não é o do rigor do conhecimento exato, mas o da prática da construção política.

\section{Notas}

1 Professora titular de Filosofia da Educação da Universidade do Estado do Rio de Janeiro (UERJ). Autora, entre outros, de Enigmas da Educação (Belo Horizonte: Autêntica, 2002) e A Escola Imaginária (Rio de Janeiro: DPA, 1997) <lvalle@uerj.br>

2 Em Platão, a figura desse especialista é o filósofo, “(...) alguém que possui um saber seguro sobre um objeto importante, e um saber fundado em princípios. Platão não chamaria um sapateiro de epistèmôn" (Castoriadis, 1999, p. 56).

3 Aristóteles retoma e sistematiza, na Ética a Nicômaco, a questão duplamente centenária que atravessou a história da democracia grega como vetor para a instituição da filosofia, da política, da educação: "Pode-se deliberar sobre tudo? Tudo é matéria de deliberação?", pergunta-se ele, para, em seguida, ponderar: não se delibera nem sobre as coisas e verdades eternas, nem sobre as coisas que são submetidas a leis estáveis, nem sobre as coisas que dependem do acaso. Mas também não se pode deliberar sobre todas as coisas humanas (não podemos deliberar, evidentemente, sobre aquelas que concernem à deliberação de outros). Sobre o que se pode, então, deliberar? "Deliberamos sobre aquilo que está em nosso poder: não sobre a natureza, a necessidade, o acaso, mas: o intelecto e tudo que é produzido pelo homem. Deliberamos sobre aquilo que está em nosso poder fazer". Em suma, podemos concluir, delibera-se sobre as coisas que têm o homem como princípio, as coisas que são criadas pelo homem. (Aristóteles. Ética a Nicômaco, III, IV, 1112 a 18 - 1113 a 14). 


\section{Referências}

ARENDT, Hannah. 1987. A Condição Humana. Rio de Janeiro: Forense Universitária.

ARISTÓTELES. [Jean Tricot]. 1990. Ética a Nicômaco. Paris: Vrin.

BALIBAR, Étienne. 1998. Identité et différence. L'invention de la conscience. Paris: Seuil.

CAMBI, Franco. 1999. História da Pedagogia. São Paulo: Ed. UNESP.

CASSIN, Barbara. 1999. Aristóteles e o lógos - contos da fenomenologia comum. Rio de Janeiro: Loyola.
CASTORIADIS, Cornelius. 1987. A Criação no domínio social-histórico. In: As Encruzilhadas do labirinto II. Os domínios do homem, pp. 227-243, Rio de Janeiro: Paz e Terra.

1999. Sur le Politique de Platon. Paris: Seuil

2000. Feito e a ser feito. Rio de Janeiro: DPA.

DESCARTES, René. s/d. Méditations, IX, 1, 26. In: Ouvres Complètes. Paris: Gallimard.

TAYLOR, Charles. 1998. Les sources du moi. La formation de l'identité moderne. Paris: Seuil. 